\title{
History of hand eczema as risk factor in developing reactions to gloves
}

Field EA. Atopy and other risk factors for UK dentists reporting an adverse reaction to latex gloves. Contact Dermatitis 1998; 38:132-136

Objective To assess the significance of a personal history of atopy and other risk factors for UK dentists reporting an adverse reaction to natural rubber latex (NRL) gloves.

Design Questionnaire survey.

Intervention A self-administered questionnaire was completed by 2535 dentists of whom 1034 (group 1) had reported an adverse reaction to NRL gloves and 1501 (group 2) had not. The signs and symptoms reported by group 1 dentists were recorded.

Outcome measures Logistic regression analysis was used to identify a set of risk factors that produced the most discrete model for a dentist reporting an adverse reaction to NRL gloves. Risk factors entered into the analysis were gender, years in clinical practice, exposure to gloves and a history of atopy (asthma, hay fever, eczema) or food allergy.

Results Dentists with a history of eczema and hand eczema in childhood were most likely to report an adverse reaction to NRL gloves.
Female dentists were more likely to develop a self-reported reaction to NRL gloves (women have a higher prevalence of hand dermatitis generally). Dentists practising for less than 10 years were at greater risk.

\begin{tabular}{|c|c|c|c|c|c|}
\hline \multicolumn{3}{|c|}{ Odds } & \multicolumn{3}{|c|}{ Odds } \\
\hline$\underline{\text { Risk Factor }}$ & Ratio & $95 \% \mathrm{Cl}$ & Risk Factor & Ratio & $95 \% \mathrm{Cl}$ \\
\hline $\begin{array}{l}\text { Hand eczema } \\
\text { as child }\end{array}$ & 1.99 & $1.36-2.92$ & Asthma & 1.64 & $1.26-2.15$ \\
\hline Eczema & 1.89 & $1.50-2.37$ & Female & 1.45 & $1.25-1.72$ \\
\hline $\begin{array}{l}<10 \text { years } \\
\text { in practice }\end{array}$ & 1.65 & $1.38-1.97$ & Hay fever & 1.40 & $1.16-1.69$ \\
\hline
\end{tabular}

Conclusion A personal history of atopy was a significant risk factor. Hand eczema in childhood carries the highest risk. Hand care, including correct glove selection and hand disinfection, should be taught to undergraduates. Dentists should choose a powder-free NRL glove, low in residual accelerators and latex proteins.

Address for reprints: A Field, Dept of Clinical Dental Sciences, Liverpool University Dental Hospital, Pembroke Place, Liverpool L3 5PS, UK.

\section{Commentary}

Forty-one percent of the dentists who responded to a questionnaire reported adverse reactions to NRL gloves. Risk factors were analysed, and, as could be expected, atopic symptoms were related to self-reported reactions to NRL gloves. An increased risk for latex allergy in atopics has been reported previously, and unspecific skin irritation also tends to be more common in atopics.

The odds ratio for dentists with childhood eczema was 2 , which is equivalent to a prevalence ratio of about 1.5 (about $50 \%$ of those with childhood eczema reporting glove-related symptoms compared with $33 \%$ of those without childhood eczema). The study is based on self-reported information obtained by questionnaires. The large number of responders, 2535 dentists, is an advantage, but unfortunately no information about the study population, except membership of the British Dental Association, is given. The response rate is not stated, and the author therefore does not make any assumptions about the prevalence of reported adverse reactions among UK dentists. It is unclear whether ongoing (point prevalence) or ever symptoms (cumulative incidence) were asked for in the present study.

In other studies, the proportion of IgE-mediated allergy to NRL seems to be small among persons reporting side effects from gloves, the majority of cases being of more unspecific nature. The author points out that diagnosing allergy can be performed only at clinical examination, including appropriate testing. Counselling of atopics who are considering a career in dentistry is a delicate matter, but the data available at present indicate that the increased risk of skin problems is not higher in dentistry than in other wet work.

This study confirms that skin problems related to protective gloves is an important problem in dentistry and much effort should be taken to find proper routines for glove use and skin protection. We feel that it is important that gloves used in dentistry have a low content of allergens. Glove materials other than NRL are available today and provide a good alternative, in particular for dentists with atopic constitution.

\section{Birgitta Meding}

Dermatology Division, National Institute for Working Life, Stockholm, Sweden

Lars Barregard

Dept of Occupational Medicine, Sahlgrenska University Hospital, Göteborg, Sweden 